\title{
Dinâmica de nodulação do siratro por diferentes manejos de corte
}

\author{
Cut height and its effect on siratro \\ (Macroptilium atropurpureum) nodule dynamics
}

'Departamento de Ciência do Solo, Universidade Federal Rural de

Pernambuco (UFRPE), Recife, PE, Brasil

2Departamento de Agronomia,

Universidade Federal Rural de

Pernambuco (UFRPE),

Av. Dom Manoel de Medeiros, $s / n$

Dois Irmãos, CEP 52171-900,

Recife, PE, Brasil

${ }^{3}$ Departamento de Zootecnia,

Universidade Federal Rural de

Pernambuco (UFRPE), Recife, PE, Brasil

4Laboratório de Biologia do Solo,

Instituto Agronômico de Pernambuco

(IPA), Recife, PE, Brasil

${ }^{5}$ Secretaria de Agricultura e

Desenvolvimento Agrărio de Alagoas

(SEAGRI), Maceiô, AL, Brasil

${ }^{6}$ Bolsista de Produtividade em

Pesquisa do CNPq - Nível 2

*Autor correspondente

凶mario.lira@depa.ufrpe.br
RESUMO: A incorporação de leguminosas é uma das principais alternativas para a recuperação de pastagens degradadas, devido à fixação biológica de nitrogênio, que ocorre nos nódulos. Este trabalho visou avaliar o efeito de três intensidades de corte e a idade das plantas sobre a dinâmica de nodulação do siratro, como forma de avaliar o efeito do manejo sobre a fixação biológica de nitrogênio. Para isto, um experimento foi conduzido em vasos transparentes, com areia e solução nutritiva sem nitrogênio. As plantas foram acompanhadas durante 165 dias em casa de vegetação e submetidas a três cortes, em um experimento em arranjo fatorial $3 \times 4$ (intensidades de corte $\mathrm{x}$ quatro avaliações destrutivas semanais, após o terceiro corte) em blocos casualizados com quatro repetições. O sistema radicular foi digitalizado semanalmente para avaliar número e tamanho de nódulos. Depois do terceiro corte, as plantas foram colhidas semanalmente, para determinar a biomassa seca da parte aérea, das raízes e de nódulos vivos, senescentes e totais. As plantas que não foram submetidas ao corte apresentaram máximo de nodulação aos 60 dias, indicando provável reciclagem interna do nitrogênio. Imediatamente após cada corte, ocorreu redução no comprimento individual dos nódulos, indicando morte dos nódulos maiores e formação de novos nódulos. O aumento do número de nódulos senescentes, não avaliado na biomassa seca, indica decomposição rápida e confirma que os nódulos podem ser um componente importante na ciclagem do nitrogênio, em pastagens que contenham siratro.

PALAVRAS-CHAVE: Manejo, nitrogênio, ciclagem, simbiose.
ABSTRACT: Legume incorporation in pastures is one of the main alternatives for degraded pastures recovery due to biological nitrogen fixation, which occurs in nodules. This work aimed to evaluate the effect of three cutting intensities and plant age on siratro nodulation dynamics as a way to evaluate management effects on biological nitrogen fixation. To this end, an experiment was conducted in transparent vases, with sand and nitrogen-free nutrient solution. Plants were followed for 165 days in a greenhouse, and submitted to three cuts, in a $3 \times 4$ (cut intensity $x$ weekly destructive samplings after the third cut) factorial arrangement experiment with four replicates. The root system was digitized weekly to evaluate nodule number and size. After the third cut, plants were collected weekly to determine aerial part, root and alive, senescent and total nodules dry biomass. Uncut plants achieved maximum nodulation at 60 days, indicating probable internal nitrogen recycling. Immediately after each cut, for both intensities, there was a strong reduction in individual nodule length. The increase in senescent nodules number, not evaluated in dry mass, indicate their rapid decomposition and confirm nodules may be an important component on nitrogen cycling in pastures with grasses and legumes.

KEYWORDS: Management, nitrogen, cycling, symbiosis. 


\section{Introdução}

O Brasil possui, atualmente, uma área de mais de 220 milhões de hectares de pastagens e grande parte destas áreas apresenta algum estágio de degradação (CHAER et al., 2011). A deficiência de nitrogênio no solo é uma das principais causas desta degradação (LIRA et al., 2006), o que torna relevante o uso de leguminosas como recurso de recuperação (BODDEY et al., 2004; HERRIDGE; PEOPLES; BODDEY, 2008).

O siratro (Macroptilium atropurpureum (DC.) Urb.) é uma leguminosa forrageira, potencialmente utilizada na recuperação de pastagens, em função de sua grande produção de matéria seca e elevada fixação de nitrogênio (MACHARIA et al., 2010). A fixação biológica de nitrogênio (FBN) por leguminosas ocorre nos nódulos, que são estruturas radiculares especificamente desenvolvidas para esta simbiose. Os nódulos podem apresentar crescimento determinado ou indeterminado (SPRENT; PARSONS, 2000), com o siratro, apresentando nódulos determinados. A diferença entre os tipos de nódulos é função do processo de infecção e crescimento (PATRIARCA et al., 2004), com consequências na longevidade do nódulo (GUINEL, 2009) e, possivelmente, na sua sobrevivência a alguns tipos de estresse ambiental, como, por exemplo, perda de grande parte da biomassa aérea da planta (MENNEER et al., 2004). Estas diferenças podem afetar a disponibilização do nitrogênio fixado pela leguminosa para a gramínea.

A disponibilização do nitrogênio da leguminosa para a gramínea pode ocorrer tanto abaixo quanto acima da superfície do solo (PIRHOFER-WALZL et al., 2011), e a transferência subterrânea pode responder por $2 \%$ a $26 \%$ da transferência total (LEDGARD; STEELE, 1992), embora Høgh-Jensen e Schjoerring (2001) relatem que, somente a deposição radicular de nitrogênio fixado biologicamente, seja semelhante a todo o nitrogênio da parte aérea.

Avaliações comportamentais da nodulação podem ser realizadas por meio de metodologias não destrutivas (COSTA et al., 2006; CAMPANHARO et al., 2010), nas quais podem ser analisados os efeitos do ambiente sobre ela (LIRA JUNIOR et al., 2005). Deste modo, o trabalho objetivou avaliar os efeitos da intensidade do corte e da idade das plantas sobre a dinâmica da nodulação do siratro.

\section{Material e Métodos}

O experimento foi conduzido durante 165 dias em casa de vegetação da Universidade Federal Rural de Pernambuco - UFRPE, em Recife, PE, avaliando o efeito da intensidade de corte e da idade das plantas sobre a nodulação do siratro (Macroptilium atropurpureum). O experimento consistiu de um arranjo fatorial $3 \times 4$ (intensidades de corte - ausência de corte, corte a $5 \mathrm{~cm}$ ou $20 \mathrm{~cm}$ de altura $\mathrm{x}$ colheitas destrutivas semanais, após o terceiro corte), em um delineamento em blocos casualizados com quatro repetições. Foram utilizados vasos em acrílico transparente, medindo $28 \mathrm{~cm} \times 20 \mathrm{~cm} \times 7 \mathrm{~cm}$ (altura $\times$ largura superior $\times$ largura da base), com drenagem livre na parte inferior dos vasos (COSTA et al., 2006). Esses vasos foram preenchidos com areia lavada e autoclavada, até os $25 \mathrm{~cm}$ de altura e envolvidos por lona plástica.

As sementes utilizadas foram desinfestadas superficialmente e pré-germinadas em condições assépticas. Sete dias após a germinação, foi realizado o transplantio, colocando-se duas plântulas por vaso, e inoculadas com $1 \mathrm{~mL}$ de caldo bacteriano com, aproximadamente, $10^{9}$ células de rizóbio $/ \mathrm{mL}$ da estirpe SEMIA 656 (GENBANK acesso AY904732) de Bradyrhizobium japonicum (MENNA, 2006). A estirpe foi cedida pela Fundação Estadual de Pesquisa Agropecuária do Estado do Rio Grande do Sul - FEPAGRO e é recomendada para produção de inoculantes para o siratro (BRASIL, 2011). Aos 15 dias pós-transplantio, foi feito desbaste, deixando-se apenas uma planta por vaso.

As plantas foram irrigadas com solução nutritiva de Hoagland, sem nitrogênio, (HOAGLAND; ARNON, 1950), a $10 \%$ de concentração, uma vez ao dia. A partir do desbaste, foram realizadas digitalizações do sistema radicular de todas as plantas, semanalmente, na resolução de 200 pontos por polegadas, 24-bits de cor nos dois maiores lados de cada pote (COSTA et al., 2006). O primeiro corte foi realizado 60 dias após o transplantio (DAT) nas intensidades de $5 \mathrm{~cm}$ e $20 \mathrm{~cm}$, conforme os tratamentos, permanecendo em crescimento livre as plantas do tratamento com ausência de corte.

Depois do corte, a biomassa colhida foi seca em estufa com circulação de ar forçada a $65^{\circ} \mathrm{C}$, para determinação da biomassa seca da parte aérea. Depois do primeiro corte, as digitalizações semanais continuaram, bem como as demais medições até os 45 e 75 dias após o primeiro corte (DAPC), quando foram realizados o segundo e o terceiro corte respectivamente, conforme citado anteriormente.

A partir do terceiro corte, foram realizadas colheitas semanais nas intensidades estabelecidas, logo após as digitalizações que foram realizadas aos 7,14, 21 e 28 dias. A cada colheita, o sistema radicular teve seus nódulos retirados separadamente, para obtenção do número de nódulos (não senescentes, senescentes e total) e medições de comprimento, diâmetro e área de nódulos (LIRA JUNIOR; SMITH, 2000), tanto nos nódulos retirados na colheita manualmente, quanto nos que foram observados nas imagens digitalizadas (COSTA et al., 2006).

A biomassa seca da parte aérea, vagens, sistema radicular, nódulos não senescentes, senescentes e totais foram determinados de forma idêntica aos cortes anteriores, sendo o teor de nitrogênio determinado pelo método Kjeldahl.

Com base nas variáveis estimadas, foram calculadas as taxas de crescimento em termos de altura, matéria seca, número de nódulos, nitrogênio total, como exemplificado abaixo para a Matéria Seca da Parte Aérea (MSPA), além de nodulação específica (NodEsp) e nitrogênio total específico (NTOTesp).

$$
\begin{gathered}
\text { MSPA Relativa }=\frac{\left(M S P A_{\text {Final }}-M S P A_{\text {Inicial }}\right)}{\text { Número dedias }}\left(g_{\text {dia }}{ }^{-1}\right) \\
\text { NodEsp }=\frac{\text { Númerototal denódulos }}{\text { Matéria seca deraízes }}\left(\text { num.m } \mathrm{m}^{-1}\right)
\end{gathered}
$$




$$
\text { Ntotesp }=\frac{\text { Ntotal }}{\text { MSNódulos }(\text { Totais })}=\frac{\text { teor } N \times M S P A}{\text { MSNódulos }(\text { Totais })}\left({\left.\mathrm{mg} . \mathrm{mg}^{-1}\right)}^{-1}\right.
$$

Para a análise dos dados de desenvolvimento dos nódulos e das plantas, foi adotado o modelo misto para análise de medições repetidas, conforme sugerido por Littell, Henry e Ammerman (1998), com escolha do modelo de matriz de covariância, feita individualmente para cada variável entre os modelos não estruturados, antedependência, autorregressivos de primeira ordem, autorregressivos de primeira ordem heterólogo, autorregressivos, com média móvel de primeira ordem, autorregressivos com média móvel de primeira ordem, heterólogos, simetria composta, simetria composta heterológa, Huyhn-Feldt, Toeplitz e linear geral pelo critério do menor valor, para AIC (Akaike Information Criteria), utilizando o SAS. Nesta análise, foi estudado apenas o efeito das diferentes intensidades de corte, em interação com a idade das plantas determinadas em relação ao primeiro corte e com os efeitos significativos para idade ou interação, avaliados por regressão não linear com base nas médias estimadas por LSMeans, utilizando-se o SigmaPlot 10. Para a colheita final, a análise foi considerada como delineamento em blocos casualizados, em arranjo fatorial $3 \times 4$, sendo três intensidades de corte (ausência de corte; $5 ; 20)$ e quatro colheitas $(7 ; 14 ; 21 ; 28$ dias após corte), com quatro repetições. Nesta análise, as variáveis com efeitos significativos foram estudadas pelo teste de comparação de médias de Tukey, a 5\% de probabilidade.

\section{Resultados e Discussão}

O número de nódulos para as plantas que não sofreram corte, (Figura 1a), foi crescente até os 150 dias, seguido por queda até o final do período experimental. As variáveis ligadas ao tamanho do nódulo apresentaram comportamento semelhante e são representadas pelo comprimento nodular na Figura 1b, com o máximo comprimento total dos nódulos, ocorrendo aos 146 dias. Por outro lado, para comprimento individual dos nódulos, o ponto máximo foi atingido aos 94 dias (Figura 1c), havendo uma contínua redução individual dos nódulos com o avanço da idade das plantas. Este ponto, em combinação com os dados agregados apresentados nas Figuras 1a e 1b, indica que, provavelmente, ocorreu senescência de nódulos, mesmo sem corte das plantas, a partir de aproximadamente, 90 dias, e que esta senescência foi parcialmente compensada pelo aparecimento de novos nódulos, mas que estes novos nódulos não foram suficientes para compensar a perda dos nódulos mais velhos. Embora as plantas tenham florescido a partir dos 60 dias, trabalhos desenvolvidos com o feijoeiro indicam atividade máxima da nitrogenase para o período de enchimento de grãos (LUQUEÑO et al., 2008), indicando que o florescimento, provavelmente, não deve ser considerado como a razão principal para o declínio na nodulação.

Enquanto o número de nódulos não foi afetado pelas alturas de corte até 42 dias pós-corte (Figura 2a), o tamanho do nódulo apresentou interação entre intensidade de corte e idade para todas suas variáveis, sendo representado apenas pelo comprimento total e individual, nas Figuras $2 \mathrm{~b}$ e $2 \mathrm{c}$.
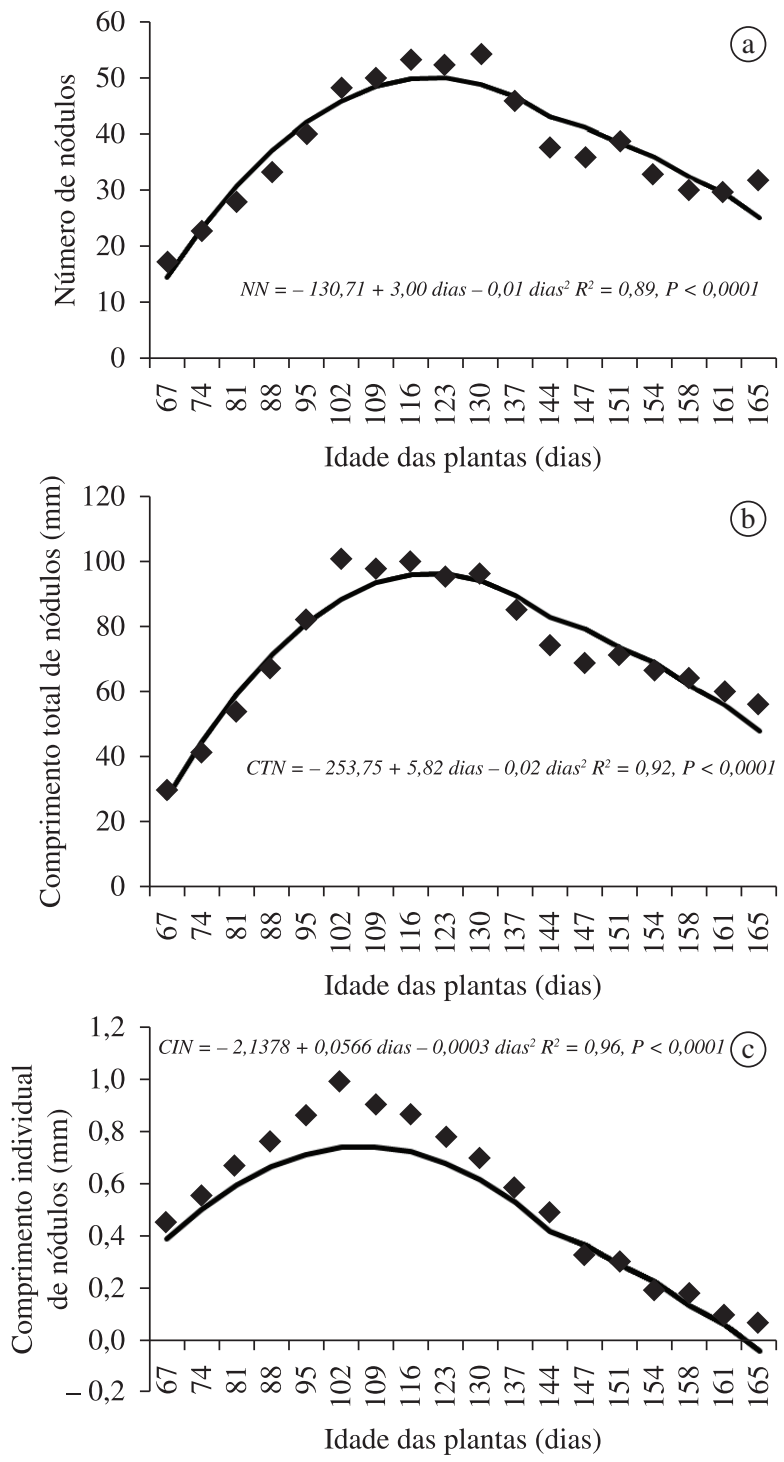

Figura 1. Desenvolvimento da nodulação em siratro que não foi submetido a cortes. a) Número de nódulos. b) Comprimento total de nódulos. c) Comprimento individual de nódulos. Os pontos indicam valores médios e as linhas, as estimativas das regressões. Todos os coeficientes das regressões foram significativos.

Os resultados para número de nódulos indicam que, nos dois tratamentos, deveria ocorrer estabilização em torno de 50 nódulos por planta aos 62 dias, indicando que o intervalo entre cortes para esta leguminosa deveria obedecer ao manejo adotado no presente trabalho, caso um dos objetivos seja maximizar a FBN. Vale ressaltar que o número máximo de nódulos estimado para plantas não submetidas a corte (Figura 1a) seria de, aproximadamente, 94 nódulos por planta. Embora não tenham sido encontrados outros trabalhos com avaliação não destrutiva da nodulação, após a imposição de cortes, alguns resultados de pesquisa indicam que cortes mais severos costumam induzir a reduções no sistema radicular, como, por exemplo, em raízes finas em Erythrina, na Costa Rica (CHESNEY, 2008), ou na FBN por Gliricidia, em Guadalupe (NYGREN et al., 2000). 


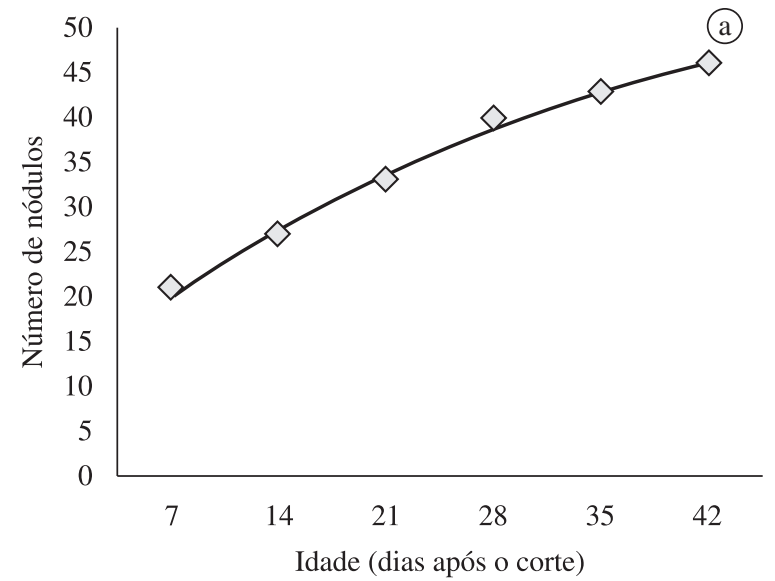

$N N=12,50+1,22$ dias $-0,01 \operatorname{dias}^{2} R^{2}=0,99, P<0,0001$

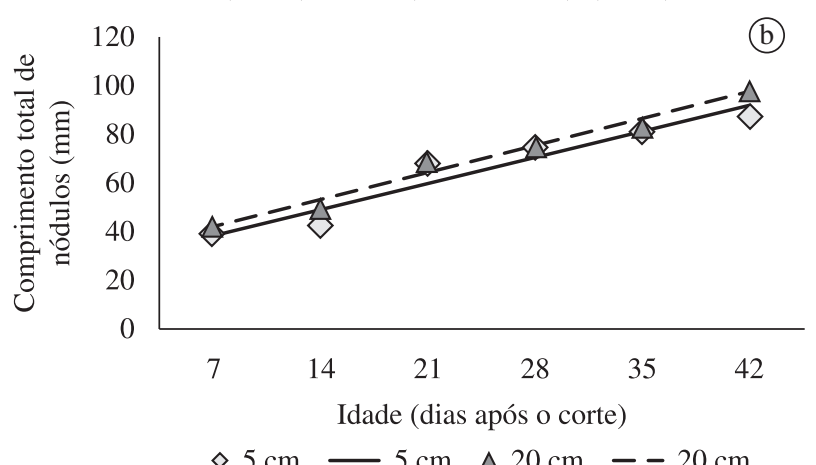

$\begin{aligned} C T N_{5}=28,98+1,48 \text { dias, } R^{2} & =0,93, P<0,0001 C T N_{20}=31,65+1,56 \text { dias, } \\ R^{2} & =0,98, P<0,0001\end{aligned}$

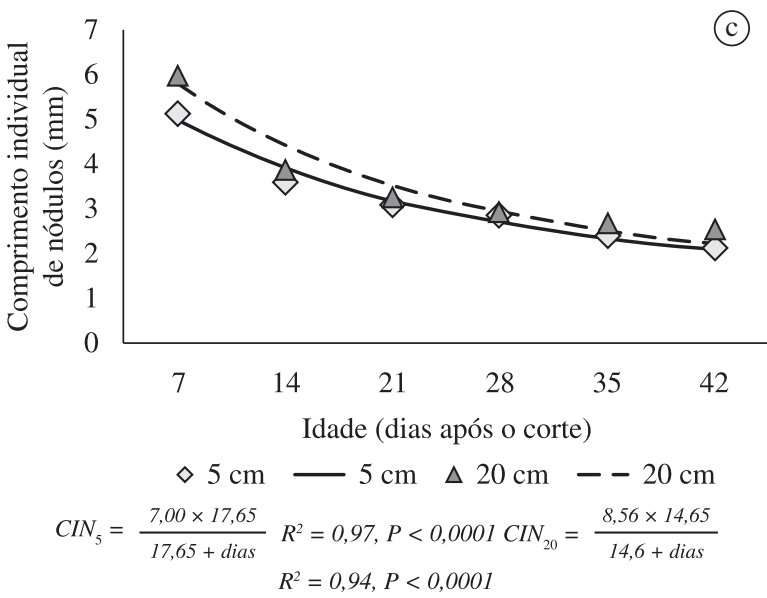

Figura 2. Desenvolvimento da nodulação em siratro submetido a corte aos $5 \mathrm{~cm}$ ou $20 \mathrm{~cm}$ de altura, após o primeiro corte. a) Número de nódulos. b) Comprimento total de nódulos. c) Comprimento individual de nódulos. Os pontos indicam valores médios e as linhas, as estimativas das regressões. Todos os coeficientes das regressões foram significativos.

No presente trabalho, os resultados obtidos para comprimento nodular, tanto total quanto individual indicam que o efeito da intensidade de corte a $5 \mathrm{~cm}$ foi mais intenso do que a $20 \mathrm{~cm}$. Este comportamento é justificável, tendo em face que para comprimento total de nódulos, a taxa de crescimento passou de $1,56 \mathrm{~mm} \cdot \mathrm{dia}^{-1}$ quando o siratro foi cortado na intensidade de $20 \mathrm{~cm}$ para uma taxa de $1,48 \mathrm{~mm} \cdot \mathrm{dia}^{-1}$ quando cortado na intensidade de $5 \mathrm{~cm}$. Diante da alta correlação entre

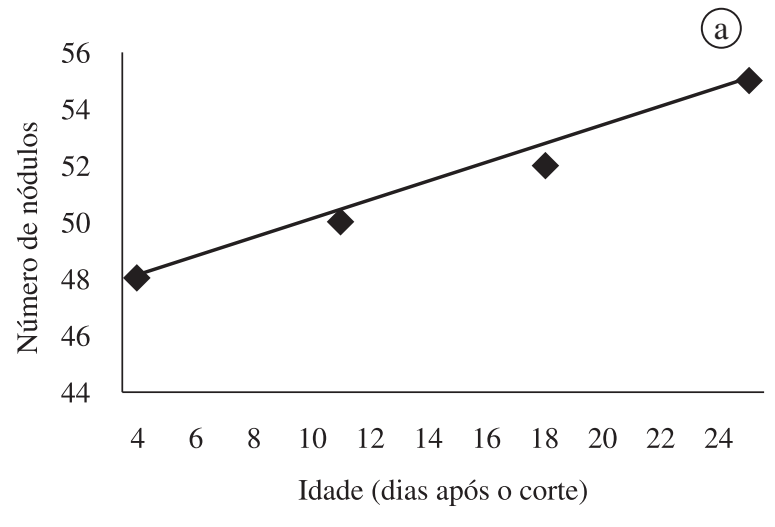

$N N=46,49+0,33$ dias, $R^{2}=0,99, P=0,0060$

(b)

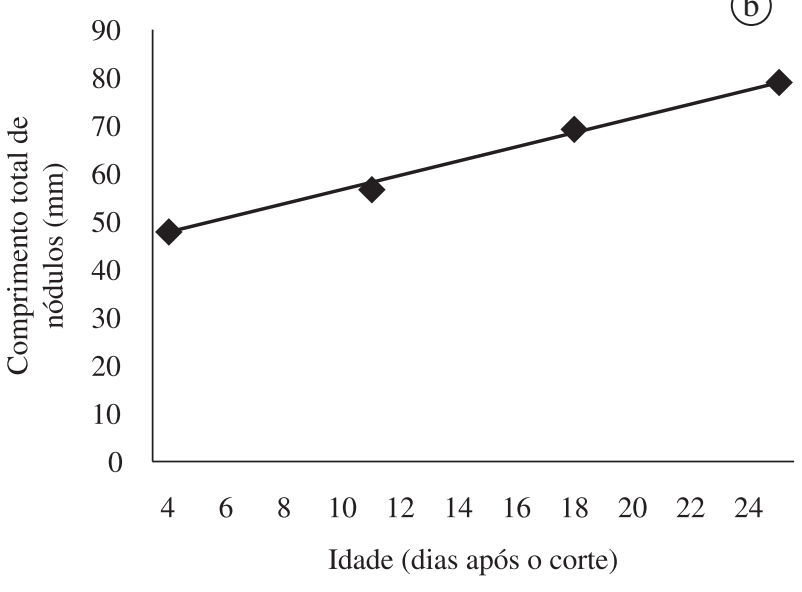

$C T N=41,42+1,50$ dias $, R^{2}=0,99, P=0,0030$

(c)

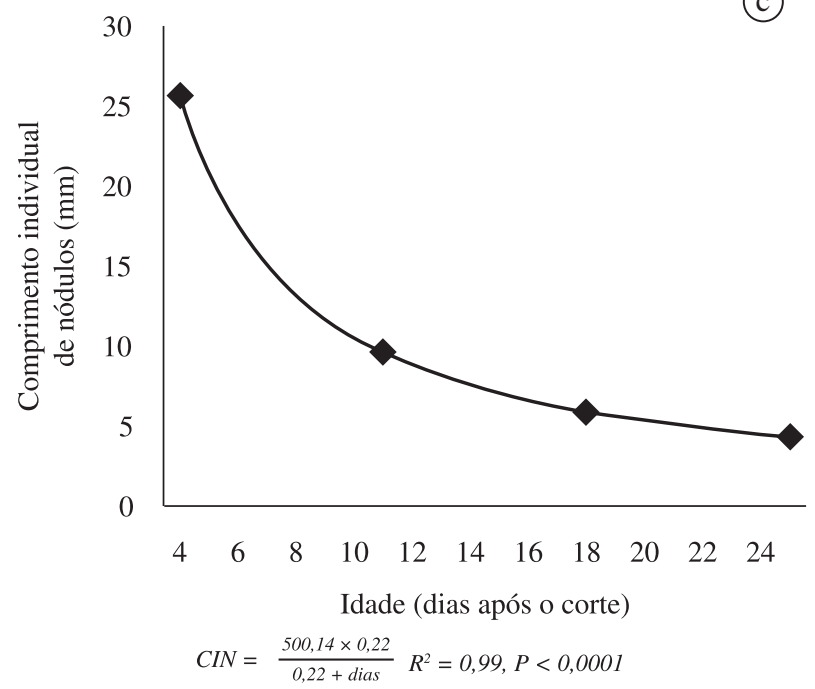

Figura 3. Desenvolvimento da nodulação em siratro, após o segundo corte a) Número de nódulos. b) Comprimento total de nódulos. c) Comprimento individual de nódulos. Os pontos indicam valores médios e as linhas, as estimativas das regressões. Todos os coeficientes das regressões foram significativos.

comprimento e massa nodular (Costa et al., 2007), e entre massa nodular e FBN (Döbereiner, 1966), é provável que as plantas cortadas a $20 \mathrm{~cm}$ de altura apresentem recuperação mais rápida da FBN em função da maior disponibilidade de fotossintatos. 
Enquanto no primeiro corte foram observadas diferenças na recuperação das plantas submetidas a diferentes intensidades de corte, o mesmo não aconteceu no segundo corte, em que foram encontrados apenas os efeitos do tempo. De forma semelhante ao primeiro corte, enquanto o número de nódulos e o comprimento total apresentaram crescimento ao longo de 24 dias pós-corte (Figuras 3a e 3b), o comprimento individual apresentou queda mais acentuada no segundo corte do que no primeiro (Figuras $2 \mathrm{c}$ e $3 \mathrm{c}$ ). Outro ponto que merece destaque é que, enquanto a taxa de crescimento do comprimento total de nódulos no primeiro corte foi de 1,48 mm.dia ${ }^{-1}$ e 1,56 mm. $\mathrm{dia}^{-1}$, das plantas cortadas nas intensidades de $5 \mathrm{~cm}$ e $20 \mathrm{~cm}$, respectivamente, no segundo corte, a taxa foi de $1,50 \mathrm{~mm}$. $\mathrm{dia}^{-1}$, independentemente da intensidade de corte, o valor foi semelhante ao obtido com corte mais intenso na primeira avaliação.

Após o terceiro corte, foi encontrado efeito significativo da intensidade de corte para as massas secas de raízes, vagens, nódulos não senescentes e senescentes, bem como para nodulação e nitrogênio total específicos (Tabela 1), enquanto o efeito da idade foi significativo para número e massa seca de nódulos senescentes (Tabela 2). Os resultados apresentados na Tabela 3 demonstram que houve interação entre os fatores para massa seca da parte aérea, teor de nitrogênio, nitrogênio total e MSPA relativa.

A biomassa seca de vagens e nódulos não senescentes, senescentes ou totais, apresentou maiores resultados para as plantas que não haviam sofrido corte (Tabela 1), como poderia ser esperado pelo menor estresse sofrido. Por outro lado, é importante destacar que os cortes estimularam a nodulação e nitrogênio total específicos, indicando possivelmente maior eficiência dos nódulos sob estresse, potencialmente em função da redução na recirculação do $\mathrm{N}$ dentro da planta.

Resultados semelhantes já foram observados por outros autores, como Dahlin e Stenberg (2010), que encontraram maior $\mathrm{N}$ acumulado na parte aérea de plantas de trevo vermelho sob corte do que na ausência de corte, bem como uma maior proporção de nitrogênio derivado da fixação para plantas cortadas do que para não cortadas. Outro resultado indicando aumento da fixação pela demanda de nitrogênio, pode ser observado na experimentação de Nyfeler et al., (2011) ao avaliar uma mistura de leguminosas (trevo branco e trevo vermelho) com gramíneas, proporcionando um teor de nitrogênio total bem mais alto do que as leguminosas separadamente.

Embora tenha ocorrido aumento não significativo no número de nódulos senescentes (Tabela 2), com pico aos 21 dias após o terceiro corte, a biomassa seca desses nódulos manteve-se aproximadamente constante até os 21 dias. Assim, é provável que a decomposição dos primeiros nódulos a senescerem tenha sido rápida o suficiente para que os nódulos senescentes de uma semana não influenciassem a nodulação da semana seguinte. É preciso ressaltar, no entanto, que essa avaliação foi destrutiva e, portanto, os mesmos nódulos pesados em uma data não poderiam ser encontrados em datas subsequentes. Essa rápida decomposição dos nódulos já havia sido observada para a leguminosa arbórea Erythrina poeppigiana por Chesney (2008).

Os dados de biomassa seca da parte aérea e conteúdo de nitrogênio (Tabela 3) para as plantas que não foram submetidas a qualquer corte confirmam os resultados observados para o desenvolvimento da nodulação (Figura 1), indicando que

Tabela 1. Biomassa seca da raiz, vagens, nódulos não senescentes, senescentes e total e nodulação e nitrogênio total específicos de siratro, submetidos a diferentes intensidades de corte, após a terceira colheita.

\begin{tabular}{|c|c|c|c|c|c|c|c|}
\hline \multirow{2}{*}{$\begin{array}{l}\text { Intensidade } \\
\text { de corte }\end{array}$} & MSR & MSV & MSNNS & MSNS & MSNT & NodEsp & NtotEsp \\
\hline & \multicolumn{2}{|c|}{$\mathrm{mg}$} & \multicolumn{3}{|c|}{ Num.mg ${ }^{-1}$} & \multicolumn{2}{|c|}{ mg.mg ${ }^{-1}$} \\
\hline Ausência & $326,0 \mathrm{a}$ & $332,9 \mathrm{a}$ & $15 \mathrm{a}$ & $140 \mathrm{a}$ & $254 \mathrm{a}$ & $2,32 \mathrm{~b}$ & $0,14 \mathrm{~b}$ \\
\hline 5 & $302,6 \mathrm{~b}$ & - & $10 \mathrm{c}$ & $114 a b$ & $233 \mathrm{~b}$ & $2,47 \mathrm{a}$ & $0,35 \mathrm{a}$ \\
\hline 20 & 314,7 a & $264,2 \mathrm{~b}$ & $13 \mathrm{~b}$ & $98 \mathrm{~b}$ & $242 b$ & $2,42 \mathrm{ab}$ & $0,23 \mathrm{ab}$ \\
\hline
\end{tabular}

MSR = biomassa seca de raiz, MSV = biomassa seca de vagem, MSNSS = biomassa seca de nódulo não senescente, MSNS = biomassa seca de nódulo senescente, MSNT = biomassa seca de nódulo total, NodEsp = nodulação específica, NtotEsp = nitrogênio total específico. Médias seguidas de mesma letra não diferem entre si ao nível de $5 \%$ de probabilidade pelo teste de Tukey. Os dados MSR, MSN, NtotEsp foram transformados por log e MSNV por $\sqrt{\mathrm{x}}$.

Tabela 2. Número e biomassa seca de nódulos senescentes em siratro submetidos a diferentes intensidades de corte, após quatro semanas de recuperação do terceiro corte.

\begin{tabular}{ccc}
\hline Épocas de colheita & NNS & MSNS (mg) \\
\hline 7 & $156 \mathrm{ab}$ & $132 \mathrm{a}$ \\
14 & $185 \mathrm{a}$ & $120 \mathrm{ab}$ \\
21 & $192 \mathrm{a}$ & $135 \mathrm{a}$ \\
28 & $118 \mathrm{~b}$ & $83 \mathrm{~b}$ \\
\hline
\end{tabular}

NNS = número de nódulo senescente, MSNS = biomassa seca de nódulo senescente. Médias seguidas de mesma letra não diferem entre si ao nível de 5\% de probabilidade pelo teste de Tukey. 
Tabela 3. Biomassa seca da parte aérea (MSPA), teor de nitrogênio, nitrogênio total (N total) e crescimento relativo (MSPA relativa) de plantas de siratro submetidas a três intensidades de corte e colheitas semanais.

\begin{tabular}{|c|c|c|c|}
\hline \multirow{3}{*}{ Idade } & \multicolumn{3}{|c|}{ Intensidade de corte } \\
\hline & Ausência & 5 & 20 \\
\hline & \multicolumn{3}{|c|}{ MSPA (g) } \\
\hline 7 & $0,67 \mathrm{aC}$ & $1,45 \mathrm{aB}$ & $6,03 \mathrm{aA}$ \\
\hline 14 & $0,66 \mathrm{aB}$ & $0,52 \mathrm{abB}$ & $3,45 \mathrm{bA}$ \\
\hline 21 & $0,67 \mathrm{aB}$ & $0,73 \mathrm{bB}$ & $2,54 \mathrm{cA}$ \\
\hline \multirow[t]{2}{*}{28} & $0,58 \mathrm{aC}$ & $1,44 \mathrm{aB}$ & $2,37 \mathrm{cA}$ \\
\hline & \multicolumn{3}{|c|}{ Teor N (\%) } \\
\hline 7 & $1,70 \mathrm{aA}$ & $1,37 \mathrm{bA}$ & $1,50 \mathrm{bcA}$ \\
\hline 14 & $1,65 \mathrm{aB}$ & $2,17 \mathrm{aA}$ & $1,84 \mathrm{abAB}$ \\
\hline 21 & $1,45 \mathrm{aB}$ & $2,13 \mathrm{aA}$ & $1,96 \mathrm{aA}$ \\
\hline \multirow[t]{2}{*}{28} & $1,41 \mathrm{aA}$ & $1,71 \mathrm{abA}$ & $1,36 \mathrm{cA}$ \\
\hline & \multicolumn{3}{|c|}{$\mathbf{N}$ total $(\mathbf{m g})$} \\
\hline 7 & $537 \mathrm{aA}$ & $138 \mathrm{bB}$ & $134 \mathrm{cB}$ \\
\hline 4 & $544 \mathrm{aA}$ & $167 \mathrm{bB}$ & $178 \mathrm{bcB}$ \\
\hline 21 & $585 \mathrm{aA}$ & $192 \mathrm{abB}$ & $195 \mathrm{bB}$ \\
\hline \multirow[t]{2}{*}{28} & $553 \mathrm{aA}$ & $231 \mathrm{aB}$ & $261 \mathrm{aB}$ \\
\hline & \multicolumn{3}{|c|}{ MSPA relativa $\left(\right.$ g.dia $^{-1}$ ) } \\
\hline 7 & $0,0396 \mathrm{aA}$ & $0,0300 \mathrm{bC}$ & $0,0362 \mathrm{bB}$ \\
\hline 14 & $0,0398 \mathrm{aA}$ & $0,0312 \mathrm{bC}$ & $0,0368 \mathrm{abB}$ \\
\hline 21 & $0,0400 \mathrm{aA}$ & $0,0308 \mathrm{bC}$ & $0,0372 \mathrm{abB}$ \\
\hline 28 & $0,0394 \mathrm{aA}$ & $0,0361 \mathrm{aB}$ & $0,0381 \mathrm{aA}$ \\
\hline
\end{tabular}

Médias seguidas de mesma letra minúscula na coluna e maiúsculas na linha não diferem entre si ao nível de 5\% de probabilidade pelo teste de Tukey.

as plantas haviam atingido um ponto máximo antes deste corte, sem crescimento posterior. Já para as plantas cortadas, o $\mathrm{N}$ total foi superior naquelas com o corte a $5 \mathrm{~cm}$, embora a MSPA tenha sido superior nas plantas com corte a $20 \mathrm{~cm}$ de altura (Tabela 3). Este maior teor de N, para plantas cuja única fonte de nitrogênio era a FBN, indica maior atividade da nitrogenase e foi observada também por outros autores, como (SERESINHE et al., 1994), que encontraram um efeito imediato da altura sobre a atividade da nitrogenase no trevo branco, mas efeito limitado sobre o conteúdo de $\mathrm{N}$.

\section{Conclusões}

A perda dos nódulos maiores, seguida por recuperação da nodulação do siratro pós-corte, confirma a importância de se avaliar a dinâmica da nodulação na ciclagem de nitrogênio em sistemas forrageiros, envolvendo gramíneas e leguminosas.

O efeito da intensidade de corte e da idade das plantas sobre a dinâmica da nodulação do siratro confirma a necessidade de avaliação do papel do manejo de corte da leguminosa neste mecanismo de ciclagem de nitrogênio em pastagens com esta forrageira.

\section{Agradecimentos}

Os autores agradecem as bolsas de mestrado da primeira autora e produtividade dos demais autores, ao Conselho Nacional de Pesquisa - CNPq e o financiamento da pesquisa à Coordenação de Aperfeiçoamento de Pessoal de Nível Superior - CAPES, através do Programa de Fomento à PósGraduação - PROF.

\section{Referências}

BODDEY, R. M. R. et al. Nitrogen cycling in Brachiaria pastures: the key to understanding the process of pasture decline. Agriculture, Ecosystems \& Environment, v. 103, p. 389-403, 2004.

BRASIL. Ministério da Agricultura, Pecuária e Abastecimento. Instrução Normativa $n^{\circ} 13$, de 24 de março de 2011. Aprova as normas sobre especificações, garantias, registro, embalagem e rotulagem dos Inoculantes destinados à agricultura, bem como as relações dos micro-organismos autorizados e recomendados para produção de inoculantes no Brasil. Diário Oficial da República Federativa do Brasil, Brasília, DF, mar. 2011. Seção 1.

CAMPANHARO, M. et al. Acidez do solo na fixação biológica de nitrogênio em feijoeiro comum. Revista Brasileira de Ciências Agrárias, v. 5, n. 3, p. 285-290, 2010. 
CHAER, G. M. et al. Nitrogen-fixing legume tree species for the reclamation of severely degraded lands in Brazil. Tree Physiology, v. 31, n. 2, p. 139-149, 2011. PMid:21378065. http://dx.doi. org/10.1093/treephys/tpq116

CHESNEY, P. Nitrogen and fine root length dynamics in a tropical agroforestry system with periodically pruned Erythrina poeppigiana. Agroforestry Systems, v. 72, n. 2, p. 149-159, 2008. http://dx.doi. org/10.1007/s10457-007-9064-7

COSTA, J. V. T. et al. Desenvolvimento de nódulos e plantas de caupi (Vigna unguiculata) por métodos destrutivo e não destrutivo. Caatinga, v. 19, n. 1, p. 11-19, 2006.

COSTA, J. V. T. D. et al. Relacionamento entre tamanho do nódulo e medições convencionais da nodulação. Acta Scientiarum, v. 29, n. 1, p. 47-54, 2007.

DAHLIN, A. S.; STENBERG, M. Transfer of N from red clover to perennial ryegrass in mixed stands under different cutting strategies. European Journal of Agronomy, v. 33, n. 3, p. 149-156, 2010. http://dx.doi.org/10.1016/j.eja.2010.04.006

DÖBEREINER, J. Evaluation of nitrogen fixation in legumes by the regression of total plant nitrogen with nodule weight. Nature, v. 210, n. 5038, p. 850-852, 1966. http://dx.doi.org/10.1038/210850a0

GUINEL, F. C. Getting around the legume nodule: I. The structure of the peripheral zone in four nodule types. Botany-Botanique, v. 87, n. 12, p. 1117-1138, 2009. http://dx.doi.org/10.1139/B09-074

HERRIDGE, D. F.; PEOPLES, M. B.; BODDEY, R. M. Global inputs of biological nitrogen fixation in agricultural systems. Plant and Soil, v. 311, n. 1-2, p. 1-18, 2008. http://dx.doi.org/10.1007/ s11104-008-9668-3

HOAGLAND, D. R.; ARNON, D. I. The water-culture method for growing plants without soil. Berkeley: California Agricultural Experiment Station, 1950.

HØGH-JENSEN, H.; SCHJOERRING, J. K. Rhizodeposition of nitrogen by red clover, white clover and ryegrass leys. Soil Biology and Biochemistry, v. 33, n. 4-5, p. 439-448, 2001. http://dx.doi. org/10.1016/S0038-0717(00)00183-8

LEDGARD, S. F.; STEELE, K. W. Biological nitrogen fixation in mixed legume/grass pastures. Plant and Soil, v. 141, n. 1, p. 137-153,1992. http://dx.doi.org/10.1007/BF00011314

LIRA JUNIOR, M. A. et al. Effect of root temperature on nodule development of bean, lentil and pea. Soil Biology and Biochemistry, v. 37, p. 235-239, 2005. http://dx.doi.org/10.1016/j. soilbio.2004.07.032

LIRA JUNIOR, M. A.; SMITH, D. L. Use of a standard TWAIN scanner and software for nodule number determination on different legume species. Soil Biology and Biochemistry, v. 32, p. 1463-1467, 2000. http://dx.doi.org/10.1016/S0038-0717(00)00052-3
LIRA, M. A. et al. Sistemas de produção de forragem: alternativas para sustentabilidade da pecuária. Revista Brasileira de Zootecnia, v. 35, p. 491-511, 2006. Número suplemento especial.

LITTELL, R. C.; HENRY, P. R.; AMMERMAN, C. B. Statistical analysis of repeated measures data using SAS procedures. Journal of Animal Science, v. 76, n. 4, p. 1216-1231,1998.

LUQUEÑO, F. F. et al. Nodule senescence and biomass components in common bean cultivars. Revista Fitotecnia Mexicana, v. 31, n. 3, p. 195-201, 2008.

MACHARIA, P. N. et al. Evaluation of forage legumes for introduction into natural pastures of semi-arid rangelands of Kenya. Grass and Forage Science, v. 65, n. 4, p. 456-462, 2010. http:// dx.doi.org/10.1111/j.1365-2494.2010.00764.x

MENNA, P. et al. Molecular phylogeny based on the 16S rRNA gene of elite rhizobial strains used in Brazilian commercial inoculants. Systematic and Applied Microbiology, v. 29, n. 4, p. 315-332, 2006. http://dx.doi.org/10.1016/j.syapm.2005.12.002

MENNEER, J. C. et al. The impact of grazing animal on $\mathrm{N}_{2}$ fixation in legume-based pastures and management options for improvement Advances in Agronomy, v. 83, p. 181-241, 2004. http://dx.doi. org/10.1016/S0065-2113(04)83004-9

NYFELER, D. et al. Grass-legume mixtures can yield more nitrogen than legume pure stands due to mutual stimulation of nitrogen uptake from symbiotic and non-symbiotic sources. Agriculture, Ecosystems and Environment, v. 140, n. 1-2, p. 155-163, 2011. http://dx.doi.org/10.1016/j.agee.2010.11.022

NYGREN, P. et al. Influence of forage harvesting regimes on dynamics of biological dinitrogen fixation of a tropical woody legume. Tree Physiology, v. 20, p. 41-48, 2000. http://dx.doi.org/10.1093/ treephys/20.1.41

PATRIARCA, E. J. et al. Organogenesis of legume root nodules. International Review of Cytology, v. 234, p. 201-262, 2004. http:// dx.doi.org/10.1016/S0074-7696(04)34005-2

PIRHOFER-WALZL, K. et al. Nitrogen transfer from forage legumes to nine neighbouring plants in a multi-species grassland. Plant and Soil, v. 350, p. 71-84, 2011. http://dx.doi.org/10.1111/j.1439037X.1994.tb00179.x

SERESINHE, T. et al. Symbiotic nitrogen fixation of white clover in a mixed sward is not limited by height of repeated cutting. Journal of Agronomy \& Crop Science, v. 172, p. 279-288,1994. http:// dx.doi.org/10.1111/j.1439-037X.1994.tb00179.x

SPRENT, J. I.; PARSONS, R. Nitrogen fixation in legume and nonlegume trees. Field Crops Research, v. 65, n. 2-3, p. 183-196, 2000. http://dx.doi.org/10.1016/S0378-4290(99)00086-6 